\title{
LEY APLICABLE AL CONTRATO DE TRABAJO INTERNACIONAL: LA PROSCRIPCIÓN DEL «ESPIGUEO NORMATIVO» (STSJ DE MADRID 10 DE MARZO 2020)
}

\author{
LAW APPLICABLE TO INTERNATIONAL EMPLOYMENT \\ CONTRACTS: PROHIBITION OF «PICK AND CHOOSE» \\ (THE DECISION OF THE HIGHER COURT OF MADRID \\ OF MARCH 24, 2018)
}

\author{
Pilar JuÁrez Pérez \\ Profesora Titular de Derecho Internacional Privado \\ Universidad Carlos III de Madrid \\ ORCID ID: 0000-0003-3044-5679
}

Recibido: 17.11.2020 / Aceptado: 14.12.2020

DOI: https://doi.org/10.20318/cdt.2021.6003

Resumen: La decisión judicial objeto de este análisis constituye un notable ejemplo de rigor y precisión en la aplicación del sistema de derecho internacional privado en el ámbito laboral. A raíz de una reivindicación salarial de unos trabajadores al servicio del Ministerio de Asuntos Exteriores en Argentina, el Tribunal aborda tanto la cuestión de la ley aplicable al contrato de trabajo como la de la prueba -o falta de ella- del derecho extranjero. En ambas materias evidencia un sólido conocimiento de las normas de derecho internacional privado y su doctrina interpretativa, de las que realiza una didáctica exposición y correctísima aplicación. Un análisis que le lleva a condenar el fraccionamiento legislativo del contrato cuando éste no es justificado, calificándolo de «espigueo de normas».

Palabras clave: contrato de trabajo internacional, ley aplicable al contrato de trabajo, prueba del derecho extranjero, modificación sustancial de las condiciones de trabajo.

Abstract: The decision at issue in this study constitutes an example of rigor and precision in the application of the private international law system on work. The Court analyzes both the question of the law applicable to the employment contract ant that of the proof -or lack of it- of foreign law, as a result of a wage claim of some workers at the service of the Ministry of Foreign Affairs. The Court shows in both subjects a solid knoweledge of the rules of private international law and its interpretative doctrine, of which he makes a didactic presentation and very correct application. This analysis leads him to criticize the legislative division of the contract, when it is not justified, naming it as «pick and choose».

Keywords: international employment contract, law applicable to the employment contract, proof of foreign law, substantial change of working conditions.

Sumario: I. El objeto del litigio: el «sueldo anual complementario» de la ley laboral argentina. II. Las (variadas) cuestiones jurídicas suscitadas en el recurso. 1. La determinación de la lex contractus. 2. La consideración de la normativa presupuestaria española como hipotética "ley de policía" del ordenamiento español. 3. La alegada falta de prueba del derecho extranjero y la respuesta del Tribunal. III. Conclusión. 


\section{El objeto del litigio: el «sueldo anual complementario» de la ley laboral argentina.}

1. Los hechos objeto del presente comentario se inician cuando un grupo de trabajadores -más de sesenta- al servicio del Ministerio de Asuntos Exteriores y Cooperación que desarrollaban su actividad laboral en Argentina, presenta ante un Juzgado de lo Social de Madrid demanda de reclamación del «sueldo anual complementario», un concepto retributivo que venían dejando de percibir, pese a encontrarse estipulado en la ley rectora de sus contratos.

2. La relación de trabajo entre los trabajadores y el Ministerio estaba sometida a la legislación laboral argentina, que regula la cuestión objeto de controversia en la Ley de Contrato de Trabajo $\mathrm{n}^{\mathrm{o}}$ 20.744. Tras definir su artículo 103 el concepto de «remuneración» ("la contraprestación que debe percibir el trabajador como consecuencia del contrato de trabajo"), el artículo 121 regula el denominado "sueldo anual complementario», que está constituido por "la doceava parte del total de las remuneraciones definidas en el artículo 103 de esta ley percibidas por el trabajador en el respectivo año calendario". La misma norma establece en su artículo 122 la forma en que ha de abonarse este sueldo complementario: en dos cuotas, la primera el treinta de junio; y la segunda, el treinta y uno de diciembre. Correlativamente, el precepto determina que el importe a abonar en cada cuota será la doceava parte de la retribución temporal devengada en el lapso temporal correspondiente.

3. Así determinado este complemento retributivo, por Acuerdo del Director General del Servicio Exterior se realizó en junio de 2015 un ajuste de las retribuciones del personal laboral de las Representaciones de España en Argentina para incluir en la nómina del mes de diciembre la cuota correspondiente del sueldo anual complementario conforme al ordenamiento laboral argentino. Sin embargo, al comenzar a pagar el sueldo anual complementario, el Ministerio redujo simultáneamente el salario mensual, de forma que total anual permanecía inalterado, y pese a que formalmente se abonada el sueldo complementario, la retribución global no se incrementaba.

4. Considerando que lo que en realidad se había producido era una reducción del salario mensual para terminar percibiendo -a través de las dos cuotas complementarias- el mismo sueldo, los trabajadores interpusieron demanda ante el Juzgado de lo Social. La sentencia de instancia estimó su pretensión, por entender que dicha redistribución mensual del salario constituía una alteración de la estructura salarial, lo que implica una modificación sustancial de las condiciones de trabajo. En consecuencia, anuló la decisión de 23 de junio de 2015, de la Dirección General del Servicio Exterior, por la que se modificaba la forma de redistribución salarial y retribución mensual de los demandantes.

5. La sentencia fue recurrida en suplicación ante el Tribunal de Justicia de Madrid (Sala de lo Social, Sección $2^{\mathrm{a}}$ ), que desestimando el recurso, se pronunció en sentido confirmatorio, sobre la base de la argumentación que seguidamente examinamos, contenida en su Sentencia núm. 252, de 20 marzo $2020^{1}$.

\section{Las (variadas) cuestiones jurídicas suscitadas en el recurso}

6. Tras desechar algunas de las consideraciones jurídicas introducidas por el Abogado del Estado en el recurso -como la eventual caducidad de la reclamación-, el Tribunal Superior de Justicia (TSJ) centra la cuestión en determinar si hubo o no una modificación sustancial ilícita de las condiciones de trabajo.

7. Hay que señalar que se aprecia cierta incoherencia en la argumentación del recurrente, que por una parte denuncia la indebida aplicación del artículo 41 del Estatuto de los Trabajadores ${ }^{2}$, alegando

\footnotetext{
${ }^{1}$ ECLI:ES:TSJM:2020:2770.

${ }^{2}$ Real Decreto Legislativo 2/2015, de 23 de octubre, por el que se aprueba el texto refundido de la Ley del Estatuto de los Trabajadores.
} 
que la normativa laboral española no puede regular los contratos de trabajo, pero al tiempo reclama la aplicación de la legislación presupuestaria española como justificación para no reconocer a los trabajadores el sueldo anual complementario del ordenamiento argentino.

8. En su opinión, el incremento salarial que implicaría la concesión de dicho sueldo supondría una modificación de las condiciones sustanciales de trabajo. Ésta constituye una facultad que el ordenamiento español atribuye al empleador, y su ejercicio resulta legítimo debido al sustento jurídico que le otorga el artículo $41 \mathrm{ET}$ : "1. La dirección de la empresa podrá acordar modificaciones sustanciales de las condiciones de trabajo cuando existan probadas razones económicas, técnicas, organizativas o de producción". El precepto parte de una decisión unilateral de la empresa de acordar, o al menos intentar introducir, modificaciones sustanciales de las condiciones de trabajo ${ }^{3}$. Lo que niega el recurrente es la posibilidad de aplicar dicha facultad -propia de la legislación española- a los contratos de trabajo afectados, que únicamente deben ser regulados por la legislación argentina. Paralelamente, sostiene que dicha normativa carece de una figura de las modificaciones sustanciales de condiciones de trabajo equivalente a la española, que permita acoger el incremento salarial reclamado.

9. De este modo, la Administración plantea la cuestión de la ley aplicable al contrato de trabajo, que considera debe ser resuelta en una única dirección: la aplicación exclusiva del ordenamiento laboral argentino. Sin embargo -y aquí la contradicción apuntada- al mismo tiempo invoca la Ley de Presupuestos Generales del Estado español como fundamento legal de la negativa a reconocer el sueldo anual complementario y sumarlo al que se venía percibiendo, pues con ello se exceden los límites del incremento salarial.

10. No quiere el Tribunal llevar por ese derrotero el debate jurídico -aunque, como se verá, termina examinando el argumento- porque discute la premisa que lo sustenta: siguiendo la estela del juez de instancia, considera el TSJ que la normativa española no resulta aplicable a estos contratos, sometidos al ordenamiento argentino, rechazando, por tanto, la posibilidad de aplicar la legislación presupuestaria española. Procede, en consecuencia, explorar las posibles vías que pudieran dar entrada a la normativa española en una relación laboral sometida al derecho argentino.

\section{La determinación de la lex contractus.}

11. Desde la perspectiva del Derecho internacional privado español, la determinación de la ley aplicable al contrato de trabajo internacional debe hacerse a través de las normas contenidas en el Reglamento (CE) No 593/2008 del Parlamento Europeo y del Consejo, de 17 de junio, sobre ley aplicable a las obligaciones contractuales ${ }^{4}$. Como es sabido, el Reglamento introduce respecto del contrato de trabajo algunas peculiaridades al régimen ordinario de designación de la lex contractus contenido en el artículo 3 , que consagra la autonomía de la libertad como criterio general de determinación ("1. El contrato se regirá por la ley elegida por las partes").

12. En materia laboral, esta regla viene matizada por el artículo 8 del Reglamento, que restringe el ejercicio de la autonomía de la voluntad con la finalidad de proteger al trabajador, equiparando su desigual posición contractual respecto del empleador ${ }^{5}$. Con este mecanismo, el Reglamento trata de garantizar que la «libertad de elección de ambas partes» no encubra un mecanismo para privar al trabajador de una protección que de otro modo hubiera tenido (esto es, si la designación de la ley aplicable al contrato se basara en criterios objetivos, no en la subjetividad de las partes).

\footnotetext{
${ }^{3}$ I. García-Perrote Escartín, Manual de Derecho del Trabajo, 10 a ed., Tirant Lo Blanch, Valencia, 2020, p. 547.

${ }^{4}$ DOUE L núm. 177, de 4 de julio de 2008.

${ }^{5}$ Sobre la orientación tuitiva del mecanismo conflictual que en el ámbito comunitario determina la ley aplicable al contrato de trabajo, vid. J. CARrascosa González, "Contrato de trabajo internacional”, en Curso de contratación internacional, A.L. Calvo Caravaca y J. Carrascosa González (coords.), Tecnos, Madrid, 2003, pp. 567-576.
} 
13. En consecuencia, el artículo 8 mantiene la autonomía individual como regla general de designación de la lex contractus, pero impone ciertos límites a dicha elección de ley. En concreto, exige que ésta no prive al trabajador de la protección que le otorguen las normas imperativas del ordenamiento que hubiera sido objetivamente aplicable, es decir, de no haber designado las partes la ley rectora del contrato. Dicho ordenamiento objetivamente aplicable será el que designe el propio artículo 8 en sus restantes puntos de conexión. De este modo, el principio de libertad de elección viene matizado por la exigencia de que el trabajador obtenga el mismo nivel de protección que con la ley aplicable en defecto de elección.

14. Aplicada al caso que nos ocupa, esta regla implica que una forma de dar entrada a la legislación española a estos contratos sometidos al ordenamiento argentino pudiera ser que aquélla resultase aplicable en virtud de la designación objetiva de la norma de conflicto contenida en el artículo 8 del Reglamento. En este sentido, el primer punto de conexión que encontramos en el precepto es el del lugar de prestación habitual del trabajo (apartado 2). Siendo Argentina dicho lugar, resulta evidente que la norma no designa al ordenamiento español como lex contractus. Tanto si la legislación laboral argentina fue libremente elegida por las partes como si fue designada por el lugar de prestación de los servicios (aspecto que la sentencia no permite deducir), ninguna de estas conexiones da cabida a la normativa española, en concreto la que permite la modificación de las condiciones laborales, incluidas las salariales.

15. El mismo artículo 8 contempla una última posibilidad, cual es la consideración de que el contrato presente "vínculos más estrechos" con la ley de un país distinto al aquel cuyo ordenamiento lo regula (apartado 3), en cuyo caso dispone que será aplicable la ley de dicho país. Procede entonces examinar si en el supuesto de autos concurre tal vinculación más estrecha entre los contratos y el Estado español, hasta el punto de dar primacía a su ordenamiento laboral.

16. Esta valoración corresponde al tribunal que conozca del litigio, que deberá tener en cuenta todos los elementos que caracterizan la relación laboral y apreciar el elemento o elementos a su juicio más significativos, como declaró la STJUE de 12 de septiembre de $2013^{6}$. En el supuesto que analizamos, subraya el TSJ que no existe causa alguna para establecer tal vinculación, al tiempo que recuerda que ninguna de las partes ha cuestionado que la ley aplicable al contrato fuera otra que la argentina.

\section{La consideración de la normativa presupuestaria española como hipotética "ley de policía" del ordenamiento español}

17. Desde la perspectiva del Derecho internacional privado, y una vez desechada la vía del artículo 8 del Reglamento Roma I, la única alternativa restante para dar entrada en los contratos de trabajo a la normativa española vendría de la mano del mecanismo previsto en el artículo 9 de mismo texto, que constituye la vía de acceso de las llamadas «leyes de policía». En consecuencia, resulta coherente plantearse si ésta podría constituir la vía para aplicar la limitación presupuestaria contenida en la legislación española a los contratos regidos por el ordenamiento argentino, tal como defiende el Abogado del Estado para justificar la negativa de la Administración a reconocer a los trabajadores el sueldo anual complementario argentino.

18. Conforme al artículo 9 del Reglamento, una ley de policía es "una disposición cuya observancia un país considera esencial para la salvaguardia de sus intereses públicos, tales como su organización política, social o económica, hasta el punto de exigir su aplicación a toda situación comprendida

\footnotetext{
${ }^{6}$ Asunto C-64/12, Anton Schlecker c. Melitta Josefa Boedeker, apartados 40 y 41 (ECLI:EU:C:2013:551). Sobre esta cuestión en el concreto supuesto del personal laboral de nacionalidad española que presta sus servicios en las embajadas españolas en el extranjero, vid. N. Marchal Escalona, "De la protección del personal laboral al servicio de las embajadas españolas", Bitácora Millennium DIPr, Revista nº 6, 2017.
} 
dentro de su ámbito de aplicación, cualquiera que fuese la ley aplicable al contrato según el presente Reglamento". Sobre esta definición, el artículo 9 establece la una doble vía de entrada a dichas disposiciones imperativas: una imperativa y la otra, facultativa. La primera se refiere a las leyes de policía del foro (art. 9.2), esto es, del tribunal que esté conociendo del litigio. La segunda vía faculta la entrada de las leyes de policía del país donde deban ejecutarse las obligaciones derivadas del contrato, dejándose su aplicación a la valoración judicial", que deberá tener en cuenta "su naturaleza y su objeto, así como las consecuencias que se derivarían de su aplicación o de su inaplicación" (art. 9.3).

19. En el presente supuesto, la aplicación de la invocada normativa presupuestaria española podría en todo caso ser aplicada a los contratos de trabajo -limitándolos salarialmente- a través de la primera opción, como ley de policía del foro (art. 9.2). Conforme a esta vía, el tribunal español debe obligatoriamente dar entrada a las disposiciones imperativas vigentes en su ordenamiento, sea cual sea la ley rectora del contrato individual de trabajo ${ }^{8}$. En el Reglamento Roma I, la finalidad de este mecanismo es garantizar la aplicación al contrato de trabajo de un standard mínimo de protección, que viene configurado por un 'núcleo duro' de normas de protección mínima, que no pueden ser eludidas por la aplicación al contrato de un ordenamiento distinto, ya sea el elegido por las partes o bien el designado objetivamente por la norma de conflicto reglamentaria9.

20. Ello plantea la espinosa cuestión de delimitar dicho núcleo duro de normas tuitivas, algo que los legisladores estatales a menudo no indican expresamente, lo que obliga a realizar un proceso de deducción a partir del contexto, contenido y finalidad de la norma. Como indican A.L. CAlvo CARAVACA y J. CARRASCOSA GONZÁLEZ, con carácter general, "las normas que pueden aplicarse a través del artículo 9 del Reglamento Roma I son las que regulan las condiciones de trabajo «en general»o las que regulan el «mercado laboral» (...) «normas institucionales laborales», que protegen intereses colectivos y generales" 10 .

21. Resulta llamativo que el Tribunal no explore esta posibilidad al valorar la pretendida aplicación de la normativa presupuestaria española invocada por el recurrente ${ }^{11}$. Por el contrario, su respuesta es mucho más concisa y contundente, al rechazar de plano dicha contingencia sobre la base de la unidad legislativa del contrato de trabajo, que impide dar entrada a cualquier otra norma que no sea la lex contractus, en este caso, la legislación argentina. Una consideración que establece el TSJ en los siguientes términos: "Lo primero que hemos de decir es que si el contrato, efectivamente, se rige por la legislación argentina y este es el fundamento esencial del recurso entonces la cita de la Ley de Presupuestos Generales del Estado está fuera de lugar, porque se trata de una norma española que no resulta de aplicación para regir la relación laboral. No puede admitirse ese pretendido espigueo para aplicar a la relación laboral normas argentinas (la Ley de Contrato de Trabajo) y españolas (las leyes presupuestarias)".

\footnotetext{
${ }^{7}$ Sobre esta cuestión, vid. L.F. CARrillo Pozo, "Tratamiento de las leyes de policía de terceros Estados. (A propósito de la sentencia del TJUE de 18 de octubre de 2016”, Bitácora Millennium DIPr, Revista n 5, 2017.

${ }^{8}$ Pero ello, siempre que concurran "consideraciones de interés público", ya que el artículo 9 del Reglamento constituye en su conjunto una excepción al principio de libre elección de la ley aplicable por las partes del contrato, siendo la finalidad de este mecanismo permitir al juez del foro, "en circunstancias excepcionales", tener en cuenta dichas consideraciones (cfr. STJUE de 13 de octubre de 2016, Asunto C-135/15, Republik Griechenland c. Grigorios Nikiforidis, apartado 43, TJCE 2020\147).

${ }^{9}$ Esta finalidad tuitiva no obsta para que el mecanismo haya sido objeto de críticas -en sede del Convenio de Roma de 1980, pero perfectamente extrapolables al régimen actual-, por generar una fuerte indeterminación del Derecho aplicable al contrato, dado el amplio margen de apreciación del juez respecto a la aplicación -y en tal caso, extensión- de la normas de terceros Estados (A.L. Calvo Caravaca y J. Carrascosa GonzÁlez, "Contratos de importación y exportación de bienes culturales", en Homenaje al profesor Juan Antonio Carrillo Salcedo, M. Vargas Gómez-Urrutia y A. Salinas de Frías (coords.), Vol. 1, 2005, p. 284. Una incertidumbre considerada por algunos Estados incompatible con los estándares mínimos de seguridad y previsibilidad jurídicas, siendo el caso de Alemania, Luxemburgo, Irlanda, Portugal y el Reino Unido, que hicieron uso de la reserva prevista en el Convenio para no aplicar este mecanismo.

10 "Contrato internacional del trabajo", en Derecho Internacional Privado, volumen II, $18^{\mathrm{a}}$ ed., Comares, Granada, 2018, p. 1166.

${ }^{11}$ Más aún, cuando sí lo hizo en un asunto de similares características, resuelto por Sentencia de 9 noviembre 2016, aunque con una argumentación sumamente criticable, a juicio de N. MARCHAL EsCALONA ("De la protección del personal laboral...", cit.).
} 
22. En este punto, la decisión del Tribunal hubiera resultado más rigurosa y exhaustiva si hubiera incluido en su razonamiento el mecanismo del artículo 9 del Reglamento antes de manifestar su negativa, puesto que resulta legítimo plantearse la eventual adecuación de la legislación presupuestaria reclamada al conjunto normativo que integra dicho precepto. Ciertamente, no parece razonable considerar que pudiera ser acogida esta vía, pues no resultaría coherente con el espíritu del propio mecanismo, cuya razón de ser es la búsqueda de una mayor protección al trabajador, siendo así que en el presente caso la aplicación del límite salarial generaría justamente el efecto contrario.

23. En consecuencia, es ésta una objeción más formal que sustantiva, que en nada empequeñece el valor de la sentencia, y que se realiza más bien desde la alta consideración que ésta merece, en atención al rigor e integridad con que aborda todas las cuestiones jurídicas suscitadas en el litigio. Y ello, hasta el punto de manifestarse el Tribunal de forma muy crítica hacia lo que considera una deficiente técnica del Abogado del Estado, cuya invocación de la normativa presupuestaria española considera vaga $^{12}$, "fuera de lugar" y realizada "sin apoyo en hechos probados".

\section{La alegada falta de prueba del derecho extranjero y la respuesta del Tribunal}

24. Como ya se indicó, la negativa de la Administración a efectuar la modificación salarial reclamada se sustentaba parcialmente en su afirmada inexistencia de un mecanismo legal que amparase dicho cambio en el ordenamiento argentino, que es el que debía regular los contratos de trabajo ( $m a$ non troppo, según vimos). Suscita así la cuestión de la falta de acreditación del derecho extranjero que legitime el incremento salarial de los trabajadores bajo el ius variandi empresarial en el contrato de trabajo.

25. Conforme a su razonamiento, al no haber quedado acreditado que en la ley laboral argentina exista el concepto de modificación sustancial de las condiciones de trabajo, su reconocimiento implícito -mediante el reconocimiento del incremento salarial- constituye una indebida aplicación a los contratos de trabajo del artículo 41 del Estatuto de los Trabajadores.

26. El Tribunal rechaza tajantemente dicha consideración sobre la base de dos argumentos: el primero, relativo a la afirmada falta de prueba del Derecho extranjero; el segundo, referido al contenido sustantivo del invocado poder de dirección, cuestión en la que -como anunciamos- finalmente entra.

27. Respecto a la falta de prueba del ordenamiento laboral argentino en este punto, que lleva al recurrente a defender la inexistencia de dicha figura en aquel sistema jurídico, el Tribunal niega la relación de causa-efecto que sustenta tal argumento. Así, reconoce que únicamente constan como probados los preceptos de la normativa argentina que regulan el concepto de remuneración y el sueldo anual complementario, así como su modalidad de abono. Sin embargo, recuerda que la regulación española sobre la alegación y prueba del derecho extranjero contenida en el artículo 281.2 LEC establece un sistema flexible que permite al juez participar en dicha tarea, que de este modo no queda encomendada a las partes de forma rígida y excluyente ${ }^{13}$.

\footnotetext{
${ }^{12}$ En efecto, esta indeterminación es censurada por el TSJ subrayando que el recurrente se limite a citar "una Ley de Presupuestos Generales del Estado de un ejercicio anual que no identifica", a la vista de lo cual, deduce el Tribunal -acaso con ironía-que siendo el fundamento de la resolución Director General del Servicio Exterior de junio de 2015, "debe ser la norma de 2015 (Ley 36/2014, de 26 de diciembre)". A mayor abundamiento, recuerda al Abogado del Estado que la así identificada normativa no constituye "una norma jurídica que pueda aplicarse de oficio en base al iura novit curia)".

${ }^{13}$ La literatura jurídica que ha suscitado la promulgación de este precepto es tan inabarcable como controvertida, hasta el punto de acoger doctrinas radicalmente encontradas sobre la carga de la prueba del Derecho extranjero. Un completísimo análisis de esta cuestión, con especial énfasis en la práctica judicial española, puede verse en A.L. CALvo CaravaCA, "Aplicación judicial del Derecho extranjero en España. Consideraciones críticas”, Revista Española de Derecho Internacional, Vol. 68/2, julio-diciembre 2016, pp. 133-156.
} 
28. En efecto, este precepto determina que "El derecho extranjero deberá ser probado en lo que respecta a su contenido y vigencia, pudiendo valerse el tribunal de cuantos medios de averiguación estime necesarios para su aplicación". En la actualidad, este -escueto- régimen de acreditación del Derecho extranjero debe completarse con la previsión incluida por la Ley 29/2015, 30 de julio, de cooperación jurídica internacional en materia civil, que vino a dar entrada a la labor de cooperación o complemento -que no de sustitución- que en este proceso incumbe a los tribunales de justicia. Así lo determina el Preámbulo V de la Ley al afirmar que "nuestro sistema se caracteriza por ser un sistema mixto que combina el principio de alegación y prueba a instancia de parte con la posibilidad de que el tribunal complete dicha prueba, valiéndose de cuantos medios de averiguación estime necesarios" ${ }^{14}$.

29. En coherencia con esta previsión, el TSJ lleva al proceso la normativa argentina sobre modificación de las condiciones laborales, en un loable y exhaustivo ejercicio de acreditación del derecho extranjero, al amparo de la facultad que le confiere el artículo 281.2 LEC a la luz de su actual interpretación. En su virtud, señala que la legislación laboral de Argentina sí permite la modificación de los contratos de trabajo (art. 71 de la Ley de Contrato de Trabajo $n^{\circ} 20.744$ ). Por tanto, la modificación del salario inicial de los trabajadores en los términos descritos no constituye, como argumenta el recurrente, una indebida aplicación del artículo 41 del Estatuto de los Trabajadores, sino que encuentra cobertura legal en la propia ley rectora de la relación laboral, que es la argentina.

30. La completud del Tribunal en la acreditación de dicho ordenamiento va más allá, al desbrozar el régimen general que éste establece en materia de modificación de los contratos contenido en su derecho civil. Y ello, en cierto modo condicionado por la invocación del recurrente a los límites presupuestarios españoles, como forma de desactivar el éxito de esta alegación. En este punto, opone el Tribunal el ordenamiento argentino permite la adecuación del contrato en el supuesto denominado de «imprevisión», equivalente a la cláusula rebus sic stantibus generalmente admitida en España por la doctrina jurisprudencial. Conforme a ello, si en un contrato la prestación a cargo de una de las partes se torna excesivamente gravosa por una alteración extraordinaria de las circunstancias existentes al tiempo de su celebración, ésta tiene derecho a plantear resolución total o parcial del contrato, o su adecuación.

31. En el presente caso, la «adecuación» consistiría en negar el incremento salarial basado en el sueldo anual complementario, por constituir para la Administración una alteración excesivamente gravosa -recuérdese la alusión a la limitación presupuestaria española- y motivada por una alteración extraordinaria sobrevenida. Niega el Tribunal la legitimidad de esta medida con un doble argumento. Por un lado, que la necesidad de cumplir una norma que se venía incumplimiento -el abono del sueldo anual complementario- en absoluto constituye una alteración extraordinaria sobrevenida que torne excesivamente onerosa la prestación a cargo del empleador. Por otro, la acreditada existencia en el ordenamiento laboral argentino de una normativa expresa sobre modificación unilateral del contrato de trabajo, que impide aplicar en este ámbito la posibilidad de resolución o adecuación del contrato reconocida en el ámbito civil.

\section{Conclusión}

32. La sentencia dictada por el Tribunal Superior de Justicia de Madrid el 10 de marzo de 2020 constituye un magnífico ejemplo de rigor y exhaustividad en la aplicación judicial del sistema de derecho internacional privado español.

\footnotetext{
${ }^{14}$ Para A. Rodríguez Benot, la previsión del artículo 33.2 de esta Ley “Los órganos jurisdiccionales españoles determinarán el valor probatorio de la prueba practicada...") no hace sino recalcar la relevancia del papel del juzgador en el ámbito de la acreditación del Derecho extranjero, (, "La ley de cooperación jurídica internacional en materia civil”, Cuadernos de Derecho Trasnacional, 8, 1, 2016p. 248).
} 
33. Por una parte, analiza la determinación de la ley rectora del contrato de trabajo a través de una precisa y didáctica aplicación del Reglamento Roma I. Al respecto, realiza un detallado análisis de la norma de conflicto contenida en su artículo 8, examinando sus distintos puntos de conexión para llegar a la conclusión de que la ley rectora de los contratos de trabajo no puede ser otra que la argentina. Esta corrección interpretativa resulta especialmente loable, por afectar a un sistema no siempre bien interpretado -incluso en ocasiones ignorado- por la práctica judicial española.

34. Pero justamente por la sistematicidad y rigor mostrados por el Tribunal en este punto, se echa de menos en su decisión un mayor desarrollo de la categórica afirmación que le lleva a rechazar la eventual aplicación de un ordenamiento distinto. En este punto, el órgano judicial se limita a negar la existencia de causa alguna que lo justifique, sin aportar ningún otro argumento en apoyo de su decisión.

35. Asimismo, desde esta perspectiva más crítica, sorprende que el Tribunal no haya explorado la posibilidad que ofrece el mecanismo del artículo 9 del Reglamento para dar entrada -de forma imperativa en el caso de la lex fori- a las llamadas «leyes de policía». Cierto es que el recurrente tampoco analiza esta vía como medio de traer al proceso la legislación presupuestaria española que invoca, por lo que no es razonable convertir esta sorpresa en reproche. Pero sí importa reseñar aquí este aspecto, cuya inclusión hubiera derivado en una sentencia más completa y de mejor corrección técnica, aspectos en los que el Tribunal se muestra enormemente crítico, al enumerar y reprochar las imprecisiones de las que en su opinión adolece el recurso. Sin perjuicio de lo cual, hay que subrayar la lucidez jurídica del rechazo a aplicar una normativa -la española- que hubiera generado un perjuicio para los trabajadores, lo que resulta profundamente coherente con la finalidad tuitiva que con carácter general inspira el sistema de determinación de la ley aplicable al contrato de trabajo internacional. 